\title{
Low Temperature Selective Oxidation of Methane using Gold- Palladium Colloids
}

Rebecca McVicker ${ }^{1}$, Nishtha Agarwal ${ }^{1}$, Simon J. Freakley ${ }^{1,2}$, Qian $\mathrm{He}^{1}$, Sultan Althahban ${ }^{3}$, Stuart H. Taylor ${ }^{1}$, Christopher. J. Kiely ${ }^{1,3}$ and Graham J. Hutchings ${ }^{1 *}$

${ }^{1}$ Cardiff Catalysis Institute, School of Chemistry, Cardiff University, Main Building, Park Place, Cardiff, CF10 3AT, UK

${ }^{2}$ Department of Chemistry, University of Bath, 1 South, Claverton Down, Bath, BA2 7AY, UK.

${ }^{3}$ Department of Materials Science and Engineering, Lehigh University, 5 East Packer Avenue, Bethlehem, Pennsylvania, 18015, USA

* To whom correspondence should be addressed. E-mail: hutch@cardiff.ac.uk 


\begin{abstract}
Methane upgrading into energy-dense liquid derivatives (such as methanol or mid-range hydrocarbons) is a highly desirable process to increase its utilisation. The selective oxidation of methane using hydrogen peroxide has been investigated using unsupported gold-palladium nanoparticles prepared using colloidal methods. The effect of the reaction conditions and the catalyst parameters have been systematically investigated. Poly(vinyl)pyrrolidone (PVP) stabilised Au-Pd colloids produce methyl hydroperoxide as the primary reaction product, which is subsequently converted to methanol with high oxygenate selectivity. The stability and re-use characteristics of the colloidal catalyst have also been assessed for methane oxidation with hydrogen peroxide.
\end{abstract}

Keywords: methane; oxidation; gold palladium; unsupported nanoparticles 


\section{Graphical Abstract}

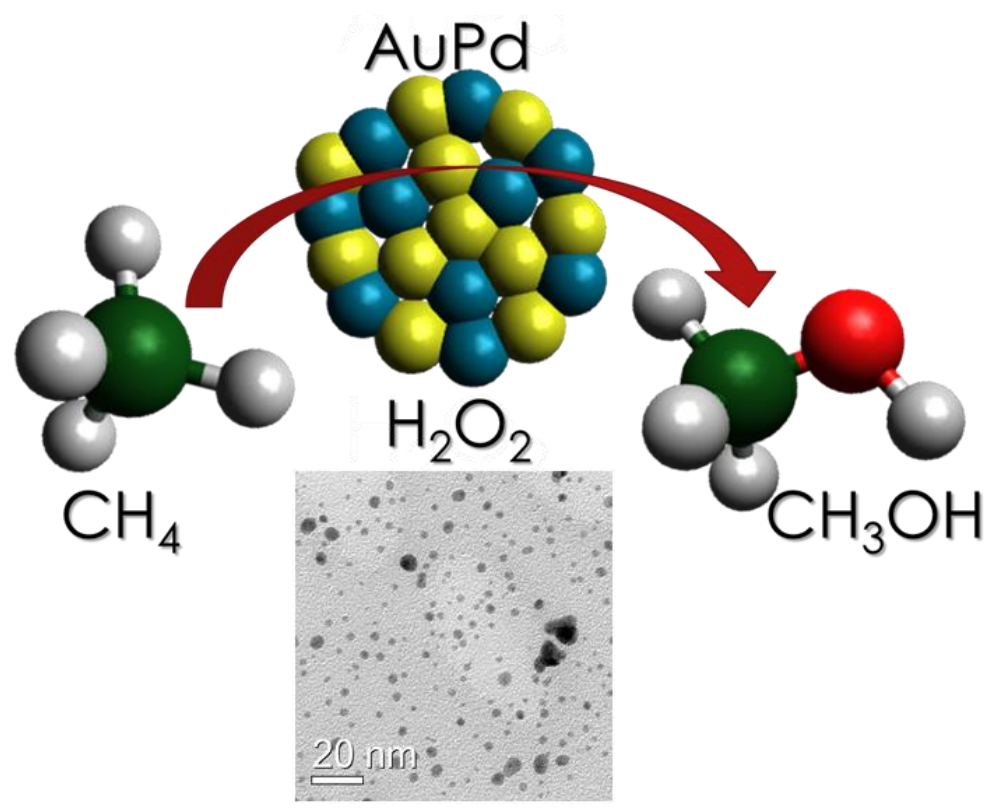

\section{Highlights}

- Au-Pd nanoparticles were synthesised using a colloidal method.

- Au-Pd bimetallic colloids exhibit high activity for methane oxidation with hydrogen peroxide.

- Transmission electron microscopy and X-ray photoelectron spectroscopy revealed alloyed nanoparticles having a narrow particle size distribution with a mean size of $2.8 \mathrm{~nm}$.

- The Au-Pd colloids showed an increase in amount of product generated with time-on-line and were found to be stable for re-use. 


\section{Introduction}

Natural gas can be considered as a versatile fuel. It currently supplies $22 \%$ of the worldwide energy demand and its use is expected to grow faster than both oil and coal [1]. Methane, our most abundant hydrocarbon, is the primary component of natural gas and is also generated as a by-product of oil refining and chemical processing. Since methane has the potential to be a carbon source for the synthesis of commodity chemicals, its transformation to other products is of utmost importance and direct activation of methane has been identified as one of the grand challenges for chemists [2]. Current industrial utilisation of methane into value-added products is performed indirectly by producing synthesis gas that can be transformed to methanol or higher hydrocarbons via Fischer-Tropsch synthesis [3].

A single-step direct activation of methane, preferably under low reaction temperature conditions, could significantly reduce processing costs thus making liquid phase approaches viable. Several high temperature gas phase routes have also been investigated over the past but have been limited due to low methanol selectivity and total oxidation to $\mathrm{CO}_{2}$ [4-7]. In the liquid phase, homogeneous catalysts based on $\mathrm{Pt}, \mathrm{Pd}$, Os have been extensively studied and provide valuable information about the mechanism of methane oxidation and active site generation [810]. However, these catalysts require harsh reaction conditions involving temperatures of at least $180^{\circ} \mathrm{C}$ with strong oxidants such as oleum and tri-fluoroacetic acid [10]. These oxidants also helped in increasing methanol selectivity at high methane conversion by protecting the product as methyl bisulphate and methyl trifluoroacetate respectively but in turn required hydrolysis of the product to obtain methanol meaning that the catalytic cycle was not closed [10,11]. Monometallic Au and Pd catalysts have also been investigated for low temperature methane oxidation $[10,12]$. However, without the presence of strong oxidants the catalysts were not effective in activating methane to produce oxygenated products. Mild oxidation in aqueous conditions with homogeneous chloroauric acid led to precipitation of $\mathrm{Au}^{0}$ and deactivation of the catalyst [9]. Methane oxidation to methanol has also been attempted using Fe-based complexes utilising more benign oxidants such as hydrogen peroxide, which generates water as the by-product. Hammond et al. have previously reported use of Fe-ZSM-5 and Cu modified Fe-ZSM-5 for methane activation to methylhydroperoxide, methanol and formic acid in aqueous media at $50{ }^{\circ} \mathrm{C}[13,14]$. 
Au-Pd catalysts prepared by sol immobilisation have been shown to be effective for primary $\mathrm{C}-\mathrm{H}$ bond activation in toluene using $\mathrm{O}_{2}$ at elevated temperatures $\left(\sim 160{ }^{\circ} \mathrm{C}\right)$ [15]. Such $\mathrm{Au}-\mathrm{Pd}$ nanoparticles have also been shown to be catalytically active for the oxidation of alcohols and the direct synthesis of $\mathrm{H}_{2} \mathrm{O}_{2}$ [16,17].The aforementioned reactions are considered to be linked by the presence of a hydroperoxy intermediate which can be formed by oxidants like $\mathrm{H}_{2} \mathrm{O}_{2}$ and tert-butyl hydroperoxide (TBHP) [8,13]. Since the formation of the hydroperoxy intermediates was also found in methane oxidation, Au-Pd alloy particles have also been tested for the methane oxidation reaction. $\mathrm{TiO}_{2}$ supported bimetallic $\mathrm{Au}-\mathrm{Pd}$ nanoparticles were shown to be active for methane oxidation at $50{ }^{\circ} \mathrm{C}$ using $\mathrm{H}_{2} \mathrm{O}_{2}$ as the oxidant $[18,19]$. The synergistic effect of gold and palladium was found to not only increase the catalytic activity but also to improve selectivity and the efficiency of the reaction. Since supported bimetallic Au-Pd catalysts have been extensively studied for the direct synthesis of $\mathrm{H}_{2} \mathrm{O}_{2}[17,20]$, they were also employed for methane oxidation using $\mathrm{H}_{2} \mathrm{O}_{2}$ produced in an in-situ fashion by using a mixture of $\mathrm{H}_{2}, \mathrm{O}_{2}, \mathrm{CH}_{4}$ and $\mathrm{N}_{2}$. A similar productivity but higher methanol selectivity was observed when using the in-situ generated $\mathrm{H}_{2} \mathrm{O}_{2}$.

Recently, Agarwal et al. demonstrated the use of unsupported Au-Pd nanoparticles for methane oxidation to methanol [21]. Higher oxygenate productivity levels of $29.4 \mathrm{~mol} \mathrm{~kg}_{\mathrm{cat}} \mathrm{h}^{-1}$ were obtained when using unsupported poly(vinyl)pyrrolidone (PVP) polymer stabilised Au-Pd colloids in the presence of $\mathrm{H}_{2} \mathrm{O}_{2}$, as compared to 0.03 mol kg cat $\mathrm{h}^{-1}$ for a conventional solimmobilised $\mathrm{Au}-\mathrm{Pd} / \mathrm{TiO}_{2}$ solid catalyst. Molecular $\mathrm{O}_{2}$ was also used as an oxidant, which resulted in an increase in oxygenate productivity to $53.6 \mathrm{~mol} \mathrm{~kg} \mathrm{cat}^{-1}$ and incorporation of $\mathrm{O}_{2}$ was demonstrated in the liquid oxygenate products [21]. In the study reported here, systematic investigations are carried out to evaluate methane oxidation reactions using the unsupported Au-Pd colloid in the presence of $\mathrm{H}_{2} \mathrm{O}_{2}$ but in the absence of $\mathrm{O}_{2}$. Au-Pd nanoparticles were synthesised via a standard colloid preparation method using PVP as the stabiliser and $\mathrm{NaBH}_{4}$ as the reductant [22]. The effect of reaction parameters (such as temperature, pressure, and stirring speed) on the catalytic activity has been evaluated. Investigations on the effect of varying the catalyst preparation parameters (such as metal concentration, chloride concentration and PVP molecular weights) have also been performed. Extended reactions were also carried out to study the evolution of the total product distribution and product selectivity in order to determine the reaction pathway.

\section{Experimental}




\subsection{Catalyst Preparation}

An aqueous solution of $\mathrm{HAuCl}_{4}$ precursor (Sigma Aldrich) and an acidic solution of $\mathrm{PdCl}_{2}$ (Sigma Aldrich) precursor (in $0.5 \mathrm{M} \mathrm{HCl}$ ) were prepared of the desired concentration in deionised water. Poly(vinyl)pyrrolidone (PVP, average molecular weight 10,000 Da, Sigma Aldrich) was added as a stabilizer to give the required metal-to-PVP ratio (typically 1:1.2 by weight). After 2-3 min of stirring, a freshly prepared $0.1 \mathrm{M} \mathrm{NaBH}_{4}$ (Sigma Aldrich) solution was added such that the molar ratio of $\mathrm{NaBH}_{4}$-to-metal was $5: 1$. This produced a dark brown colloid that was the left stirring for 30 minutes to ensure all the metal precursor salts were reduced to metallic nanoparticles. At this stage, colloid preparation was complete, and the material was stored in glass media bottles prior to use.

\subsection{Catalyst Testing}

Methane oxidation was carried out in a $50 \mathrm{~mL}$ Teflon-lined stainless steel Parr autoclave reactor [13,21]. The reactor was charged with $10 \mathrm{~mL}$ of colloid and $\mathrm{H}_{2} \mathrm{O}_{2}$ (Sigma Aldrich, 50\% wt in water). The charged autoclave was then sealed and purged three times with methane (99.999\%, Air Products). It was then pressurized with methane (to 30 bar) and heated to $50{ }^{\circ} \mathrm{C}$. Once the reactor had reached the set temperature, stirring at $1500 \mathrm{rpm}$ was commenced. After 30 min heating and stirring the reaction was stopped and the reactor vessel was cooled to below $10{ }^{\circ} \mathrm{C}$ using an ice bath. The gas containing the reaction products was removed for analysis in a gas-sampling bag.

\subsection{Product Analysis}

The amount of $\mathrm{H}_{2} \mathrm{O}_{2}$ remaining at the end of each reaction was quantified by titrating a portion of the reaction mixture against acidified $\mathrm{Ce}\left(\mathrm{SO}_{4}\right)$ solution of known concentration using ferroin as indicator. The only gas phase product of the reactions was $\mathrm{CO}_{2}$, which was quantified by GC using a Varian 450-GC equipped with FID \& TCD detectors, a methaniser and CP-SiL5CB column (50m, 0.33mm diameter, He carrier gas). ${ }^{1} \mathrm{H}-\mathrm{NMR}$ studies were carried out to quantify the amounts of liquid phase products (see SI Table S1) using a Bruker $500 \mathrm{MHz}$ NMR equipped with a solvent suppression system to minimise the signal arising from the aqueous solvent (see SI Figure S1). An internal standard containing $1 \% \mathrm{TMS}$ in $\mathrm{CDCl}_{3}(99.9 \% \mathrm{D})$ was placed in a sealed tube and used to quantify the amount of product after calibration against known standards. 


\subsection{Catalyst Characterisation}

\subsubsection{UV-visible Spectroscopy}

UV-vis spectra were recorded on a Jasco V-570 UV/VIS/NIR spectrophotometer over a wavelength range of $200-700 \mathrm{~nm}$ using a data interval of $1 \mathrm{~nm}$. Samples were placed in quartz cuvettes for analysis which was carried out at room temperature.

\subsubsection{X-ray Photoelectron Spectroscopy}

A Kratos Axis Ultra DLS photoelectron spectrometer was used to collect XPS spectra using a monochromatic $\mathrm{Al} \mathrm{K} \alpha$ X-ray radiation source operating at a power of $120 \mathrm{~W}$. Colloidal samples were pipetted onto clean glass slides and the residual solvent removed by the pumping system of the fast entry airlock of the spectrometer. Data was collected with pass energies of $160 \mathrm{eV}$ for survey spectra, and $40 \mathrm{eV}$ for the high-resolution scans with step sizes of 1 and $0.1 \mathrm{eV}$ respectively. All samples were analysed using a slot aperture and in hybrid spectroscopy mode, which utilizes both magnetic and electrostatic lenses; in this mode, the analysis area is a 700 $\mu \mathrm{m} \times 300 \mu \mathrm{m}$ rectangle. For all samples, the Kratos immersion lens system was used for charge neutralization and the spectra subsequently referenced to the $\mathrm{C}(1 \mathrm{~s})$ line taken to be $285 \mathrm{eV}$. The sample also exhibited a peak at $99.4 \mathrm{eV}$ which corresponded to the elemental $\mathrm{Si}(2 \mathrm{p})$ peak arising from the $\mathrm{SiO}_{2}$ substrate.

\subsubsection{Electron Microscopy}

Materials for TEM analysis were prepared by dispersing the colloid onto a continuous carbon film supported on a 300-mesh copper TEM grid and allowing the solvent to evaporate Specimens were examined using the bright-field imaging mode in a JEOL 2000FX transmission electron microscope operating at $200 \mathrm{kV}$ equipped with an Oxford Instruments X-ray energy dispersive (XEDS) spectrometer system.

\section{Results and Discussion}

\subsection{Catalyst Characterisation}


The colloidal catalyst was characterised using a variety of techniques. UV-vis spectroscopy (Figure S2) was used to confirm the colloid formed was a Au-Pd alloy and not a physical mixture of $\mathrm{Au}$ and Pd nanoparticles. The broad plasmon band between 500-550 nm that is normally associated with Au nanoparticles was found to be absent in the bimetallic colloids indicating the formation of an alloy rather than gold and palladium nanoparticles $[15,22]$. The colloidal catalyst was also characterised by transmission electron microscopy to determine the particle size distribution of the nanoparticles (Figure 1A). Unsupported nanoparticles were found to have a narrow particle size distribution with a mean diameter of $2.8 \mathrm{~nm}$. The colloidal Au-Pd prepared with PVP has been observed to primarily consist of multiply twinned icosahedral structures [21,23].

XPS was used to analyse the colloidal samples and is shown in Figure 1B. XPS analysis showed both $\mathrm{Au}$ and $\mathrm{Pd}$ to be metallic in nature with the presence of minor $\mathrm{PdCl}_{2}$ components. The bimetallic Au-Pd colloid showed interactions between the Au and Pd since a negative shift in binding energies was observed when compared to the monometallic colloids (Figure S3). This shift is attributed to a charge transfer from $\mathrm{Pd}$ to $\mathrm{Au}$ and is known to increase the $\mathrm{Au} s$ state occupancy indicating alloy formation [24,25].

\subsection{Catalytic Activity}

Previously, methane oxidation was carried out with aqueous $\mathrm{Au}-\mathrm{Pd}$ colloids in the presence of molecular $\mathrm{O}_{2}$ and a small amount of $\mathrm{H}_{2} \mathrm{O}_{2}$ at $50{ }^{\circ} \mathrm{C}$ [21]. It was shown that molecular oxygen was acting as the oxidant, but reactions performed in the absence of $\mathrm{H}_{2} \mathrm{O}_{2}$ showed no generation of oxygenated products, confirming that $\mathrm{H}_{2} \mathrm{O}_{2}$ was necessary to initiate the reaction. Hence, reactions have been carried out with excess $\mathrm{H}_{2} \mathrm{O}_{2}(5 \mathrm{mmol})$ as the oxidant for different times to investigate temporal selectivity towards reaction products between 5-240 min. The evolution of the overall product distribution as a function of time, along with oxygenate selectivity towards different products, is shown in Figure 2. As the reaction proceeded, the total amount of reaction products generated also increased over time. A high selectivity towards methyl hydroperoxide was observed for short reaction times, but this gradually decreases with timeon-line. The reaction was performed for $10 \mathrm{~min}$ with $1 \mathrm{mmol}$ and this also showed a high selectivity to methyl hydroperoxide (Table S2 Entry 1). Methanol was also observed in this case which indicates that the primary product of the reaction is methyl hydroperoxide, which subsequently is converted to methanol over time. Methylhydroperoxide and methanol are 
subsequently oxidised to form formic acid, demonstrating that the reaction proceeds through the same series of intermediates which were observed in previous studies with Au-Pd colloids when using both $\mathrm{H}_{2} \mathrm{O}_{2}$ and $\mathrm{O}_{2}$ [21]. Scheme 1 shows the proposed reaction pathway and suggests the final over-oxidation product of all three liquid oxygenates to be $\mathrm{CO}_{2}$, the amount of which was observed to increase over time. Along with this, a decrease in oxygenate selectivity from $94 \%$ after $30 \mathrm{~min}$ to $61 \%$ after $240 \mathrm{~min}$ was observed due to the overoxidation. After $4 \mathrm{~h}$, most of $\mathrm{H}_{2} \mathrm{O}_{2}$ was consumed and methyl hydroperoxide was found to have been transformed into methanol and formic acid. This is in line with the observations reported previously for supported AuPd catalysts [26,27]. It is also interesting to note that the same intermediates have also been reported for $\mathrm{CH}_{4}$ oxidation reactions with $\mathrm{H}_{2} \mathrm{O}_{2}$ using $\mathrm{Fe}$ and $\mathrm{Cu}$ based zeolite catalyst systems which could suggest similar reaction pathways are in operation $[13,18,28,29]$. In a previous study by Chadwick and co-workers, formaldehyde was also observed as a product [29]. As shown in Figure S1, formaldehyde was not observed in our reactions; however since the signal for formaldehyde (methane diol, s, $\delta=4.8 \mathrm{ppm}$ ) could be obscured by the broad water signal, its presence or absence of formaldehyde could not be confirmed in our study.

Two consecutive reactions were carried out with the Au-Pd colloid over 10 min. intervals to evaluate the stability of the colloids over short reaction times (SI, Table S2). After an initial 10 min of reaction, a sample was taken for analysis and the $\mathrm{H}_{2} \mathrm{O}_{2}$ was replenished to run a second reaction immediately afterwards. The results shown in SI, Table S2 demonstrate that double the total amount of products are produced after two sequential 10 min reactions, then after the first $10 \mathrm{~min}$ reaction alone indicating that the TOF and productivity of the colloids is maintained over multiple reaction cycles.

Time-on-line analysis also included a reaction which was halted after 0 min (i.e. when the reactor had reached $50{ }^{\circ} \mathrm{C}$ ) to determine if there was any product generation at lower temperatures during the reactor heat-up stage. As shown in Figure 2, $15 \mu \mathrm{mol}$ of products were formed before a temperature $50{ }^{\circ} \mathrm{C}$ was even reached. This lack of induction period was also previously observed with PVP stabilized Au-Pd colloids where products were obtained at room temperature [21].

Reactions were also carried out with $\mathrm{H}_{2} \mathrm{O}_{2}$ as the oxidant at various temperatures ranging from $5{ }^{\circ} \mathrm{C}$ to $90{ }^{\circ} \mathrm{C}$ (Figure 3 ). A total of $4.5 \mu \mathrm{mol}$ of products were obtained at $5{ }^{\circ} \mathrm{C}$ with high 
oxygenate selectivity of $87 \%$ and only $0.6 \mu \mathrm{mol}$ of $\mathrm{CO}_{2}$ produced. As the temperature was increased, the conversion of methane increased. However, the increase in the reaction temperature also caused a substantial decrease in the selectivity to the desired liquid oxygenated products from $87 \%$ to $40 \%$ at $90{ }^{\circ} \mathrm{C}$. This is caused by the increased rate of overoxidation to $\mathrm{CO}_{2}$, which has been previously observed for $\mathrm{CH}_{4}$ oxidation reactions at higher temperature [27]. The activation energy for methane oxidation with $\mathrm{H}_{2} \mathrm{O}_{2}$ was calculated as 18 $\mathrm{kJ} / \mathrm{mol}$. This activation energy value was lower than that for reactions carried out with unsupported Au-Pd-PVP colloids in presence of molecular $\mathrm{O}_{2}$ [21]. No residual $\mathrm{H}_{2} \mathrm{O}_{2}$ was detected after $30 \mathrm{~min}$ at temperatures above $70^{\circ} \mathrm{C}$ which might be due to an increase in thermal degradation [30].

Further investigations were carried out by varying other reaction parameters. The effect of varying methane pressure and thus the amount of the dissolved reactant was studied at $50{ }^{\circ} \mathrm{C}$ with Au-Pd-PVP colloids in the presence of $1000 \mu \mathrm{mol} \mathrm{H}_{2} \mathrm{O}_{2}$. The solubility of methane was found to be $0.74 \mathrm{~g}\left(\mathrm{CH}_{4}\right) / \mathrm{kg}\left(\mathrm{H}_{2} \mathrm{O}\right)$ at $50 \mathrm{bar}$, which is higher than $0.3 \mathrm{~g}\left(\mathrm{CH}_{4}\right) / \mathrm{kg}\left(\mathrm{H}_{2} \mathrm{O}\right)$ at $30 \mathrm{bar}$ [31,32]. Thus, a series of $\mathrm{CH}_{4}$ oxidation reactions were carried out where different pressures of $\mathrm{CH}_{4}$ between 10 and 50 bar were employed. The results of these reactions are shown in Figure 4. It was found that increasing $\mathrm{CH}_{4}$ pressure resulted in a very significant increase from 9.8 to $35 \mu \mathrm{mol}$ in the total amount of products formed. Oxygenate selectivity was also improved by roughly $11 \%$ on increasing the $\mathrm{CH}_{4}$ pressure from 10 to 40 bar. At 5 bar total pressure, a high $\mathrm{CO}_{2}$ selectivity was observed which corresponded to an oxygenate selectivity of only $30 \%$. Conversely, at higher $\mathrm{CH}_{4}$ pressures, a high selectivity to primary oxygenates was observed with oxygenate selectivity reaching $>90 \%$ at a pressure of 30 bar. The initial $\mathrm{H}_{2} \mathrm{O}_{2}$ concentration employed was also varied systematically in order to probe its influence on methane oxidation activity. Compared to previous studies, a similar activity trend was observed on varying the $\mathrm{H}_{2} \mathrm{O}_{2}$ concentration (Figure 5) [21]. As the initial $\mathrm{H}_{2} \mathrm{O}_{2}$ concentration is increased, oxygenate selectivity remains high (>85\%) while the percentage of $\mathrm{H}_{2} \mathrm{O}_{2}$ remaining decreases from 35 to $18 \%$ across the concentration range investigated. In agreement with previous studies, it was also found that higher initial concentrations of $\mathrm{H}_{2} \mathrm{O}_{2}$ resulted in an increase in the total amount of products formed [13,21]. Increasing the initial $\mathrm{H}_{2} \mathrm{O}_{2}$ concentration from 500 to $5000 \mu \mathrm{mol}$ yielded an increase of roughly $10 \mu \mathrm{mol}$ in the total amount of products generated. Further increasing the $\mathrm{H}_{2} \mathrm{O}_{2}$ concentration beyond $5000 \mu \mathrm{mol}$ did not result in any more products being generated. It was also found that increasing the initial $\mathrm{H}_{2} \mathrm{O}_{2}$ concentration reduced the efficiency of $\mathrm{H}_{2} \mathrm{O}_{2}$ usage. The ratio of $\mathrm{H}_{2} \mathrm{O}_{2}$ consumed-to- 
products generated increased from 24 to 383 when the initial $\mathrm{H}_{2} \mathrm{O}_{2}$ concentration was increased from $500 \mu \mathrm{mol}$ to $10,000 \mu \mathrm{mol}$.

Figure 6 shows the results for $\mathrm{CH}_{4}$ oxidation reactions carried out with colloidal $\mathrm{Au}-\mathrm{Pd}$ nanoparticles, where a range of different stirring speeds was employed. No significant change in the amount of products generated and no clear trend in oxygenate selectivity and activity was observed on varying the stirring speed. These results imply that the reaction is not mass transport limited. However, a significant increase in the $\mathrm{H}_{2} \mathrm{O}_{2}$ decomposition rate was observed upon increasing the stirring speed. Nearly $40 \%$ of the initial $\mathrm{H}_{2} \mathrm{O}_{2}$ remained after 30 min of reaction time when the stirring speed was set to $250 \mathrm{rpm}$, whereas only $10 \%$ remained at the end of the reaction when using a stirring speed of $1500 \mathrm{rpm}$. At stirring speeds of $1000 \mathrm{rpm}$, the highest total amount of products were observed. These optimised parameters were combined to achieve even higher total product amounts of $42 \mu \mathrm{mol}$ and a higher TOF of 11.2 $\mathrm{h}^{-1}$ (as compared to $4.2 \mathrm{~h}^{-1}$ when the reaction was performed under standard conditions) (SI, Table S3). A reaction was performed at $60{ }^{\circ} \mathrm{C}$ with 40 bar $\mathrm{CH}_{4}$ pressure and a high selectivity $(=81 \%)$ to oxygenated products was maintained. However, the oxidant usage was found to be less efficient under the optimised conditions in relation to the ratio of $\mathrm{H}_{2} \mathrm{O}_{2}$ consumed-toproducts generated, increasing from 36 to 110 when compared to a reaction carried out under standard conditions. The optimised reaction was carried out with $5000 \mu \mathrm{mol}$ of $\mathrm{H}_{2} \mathrm{O}_{2}$ which resulted in lower efficiency of $\mathrm{H}_{2} \mathrm{O}_{2}$ usage. These observations are in line with our previous study on the effect of $\mathrm{H}_{2} \mathrm{O}_{2}$ concentration on methane oxidation activity [21].

An investigation into effect of metal concentration was carried out by conducting reactions by diluting the colloid sample with water. Samples of a typical Au-Pd colloid ([metal $]=7.57 \times 10^{-}$ ${ }^{4} \mathrm{M}$ ) were diluted to $3.79 \times 10^{-4} \mathrm{M}$ and $1.89 \times 10^{-4} \mathrm{M}$ and were used to carry out $\mathrm{CH}_{4}$ oxidation reactions. It was considered preferable to dilute a standard colloid rather than prepare new colloids with different metal concentrations in order to avoid any possible effects that altering the metal concentration during nanoparticle preparation might have on particle size or composition. The results are presented in Figure 7 and show that changing the metal concentration in the reactor has minimal effect on both $\mathrm{H}_{2} \mathrm{O}_{2}$ consumption and on the selectivity towards oxygenated products. The total amount of products produced, however, appears to increase linearly with metal concentration, which might be due to removal of mass transfer limitations due to removal of support, which was also observed in $\mathrm{CH}_{4}$ oxidation in the 
presence of $\mathrm{O}_{2}$ [21]. The reaction with a metal concentration of $1.89 \times 10^{-4} \mathrm{M}$ produced $18 \mu \mathrm{mol}$ of products, which increased to $23 \mu \mathrm{mol}$ when the metal concentration was raised to $7.57 \times 10^{-4}$ M. Since the colloidal catalysts were prepared using metal chloride precursors, any change in metal concentration could also lead to a change in the $\mathrm{Cl}$ concentration, it was necessary to investigate the effect of $\mathrm{Cl}$ concentration on the activity of the colloids without modifying the metal concentration. With this aim in mind, reactions were carried out with a standard $\mathrm{Au}-\mathrm{Pd}$ colloid having a metal concentration of $7.57 \times 10^{-4} \mathrm{M}$ where various amounts of $\mathrm{NaCl}$ were added to the reactor (Figure 8). The $\mathrm{H}_{2} \mathrm{O}_{2}$ consumption and selectivity to oxygenated products remained stable throughout the investigation. No clear trend was observed for the total amount of products generated as the sodium chloride concentration increased. Overall it is clear that increasing the $\mathrm{Cl}$ concentration in this system does not have a beneficial effect on the activity of the Au-Pd nanoparticles. From these results, it can be concluded that the increase in the amount of products generated upon increasing the metal concentration for this system was not the caused by the concurrent increase in $\mathrm{Cl}$ concentration.

Another parameter that was studied was the effect of varying the amount of stabilising polymer employed. The Au-Pd colloid used in these reactions was prepared with PVP having a molecular weight (number average) of $10 \mathrm{kDa}$. Three colloids were prepared using the sol method employing the same metal concentration of $7.57 \times 10^{-4} \mathrm{M}$, but using various molecular weights of PVP. Comparative methane oxidation experiments were then carried out using these colloids and $\mathrm{H}_{2} \mathrm{O}_{2}$ as the oxidant as shown in Figure 9. A slight increase in the amount of products generated was observed as molecular weight of the PVP used was increased. Increasing the PVP molecular weight from 3.5 to $40 \mathrm{kDa}$ results in an increase of $10 \mu \mathrm{mol}$ in the total products generated, but further increasing the PVP molecular weight from 40 to 360 $\mathrm{kDa}$ only created an extra $2 \mu \mathrm{mol}$ of products. Again, only a moderate improvement from 85 to $98 \%$ was observed in oxygenate selectivity considering the PVP molecular weight was increased by two orders of magnitude from $3.5 \mathrm{kDa}$ to $360 \mathrm{kDa}$. The measured $\mathrm{H}_{2} \mathrm{O}_{2}$ consumption was unaffected by changing in PVP molecular weight from 10 to $360 \mathrm{kDa}$, although the $3.5 \mathrm{kDa}$ PVP colloid consumed 20\% less oxidant than the other colloid catalysts tested. Overall, these results indicate that varying the PVP molecular weight in the stabilising ligand only had a modest effect on the activity of the Au-Pd colloid catalyst.

\section{Conclusions}


Methane oxidation reactions have been carried out in the presence of $\mathrm{H}_{2} \mathrm{O}_{2}$ and colloidal AuPd nanoparticles prepared using PVP as a stabilising ligand. These reactions were found to proceed via the same reaction pathway as for $\mathrm{CH}_{4}$ oxidation reactions catalysed by supported $\mathrm{Au}-\mathrm{Pd}$ nanoparticles. In both systems, $\mathrm{CH}_{3} \mathrm{OOH}$ is produced as the primary product which undergoes subsequent transformation to form $\mathrm{CH}_{3} \mathrm{OH}$ and $\mathrm{HCOOH}$ before complete oxidation to $\mathrm{CO}_{2}$. Reactions were also carried out at different temperatures, demonstrating the efficacy of unsupported Au-Pd colloids at room temperature. An activation energy of $18 \mathrm{~kJ} / \mathrm{mol}$ was calculated from analysis of the reaction kinetics. Further investigations were performed in order to optimise individual reaction parameters such as $\mathrm{CH}_{4}$ pressure, oxidant concentration and stirring speed. The $\mathrm{CH}_{4}$ oxidation reaction when carried out by combining the results of our optimisation study, resulted in a high productivity value of $74.4 \mathrm{~mol} \mathrm{~kg}^{-1} \mathrm{cat} \mathrm{h}^{-1}$. This demonstrates the high intrinsic activity of unsupported Au-Pd nanoparticles for this particular reaction. This productivity value also compares very favourably to methane monooxygenase (MMO) and Fe-Cu/ZSM-5 catalysts which have productivities of $5.1 \mathrm{~mol} \mathrm{~kg}^{-1} \mathrm{cat}^{-1}$ and 16.5 mol kg${ }^{-1}$ cat $\mathrm{h}^{-1}$ respectively $[13,14,33]$. However, it should be noted that MMO utilises oxygen as the terminal oxidant and this remains the target for catalyst design as the current study uses $\mathrm{H}_{2} \mathrm{O}_{2}$ as an initiator to enable $\mathrm{O}_{2}$ to be utilised [21,34,35].

Studies carried out to monitor the effects of parameters associated with the preparation procedure found that increasing the metal concentration of the Au-Pd colloids employed resulted in an increase in the amount of products generated during a reaction. Changes in $\mathrm{Cl}$ concentration was found to have no significant effect on the catalytic activity. However, some increase in activity was observed on increasing the molecular weight of polymer PVP used in the stabilising ligand, but it was only a modest effect considering that the change in PVP molecular weight investigated was over two orders of magnitude.

Overall, the colloidal Au-Pd nanoparticles, in the presence of $\mathrm{H}_{2} \mathrm{O}_{2}$ have been found to be effective catalysts for $\mathrm{CH}_{4}$ oxidation, and a better mechanistic understanding has been attained through systematic investigation of various parameters associated of the system. It has been shown that even though the Au-Pd nanoparticles display a high level of intrinsic activity for this reaction, further exploitation of unsupported nanoparticles as catalysts for industrial use will necessitate an investigation into the factors effecting colloid stability. 


\section{Acknowledgements}

We acknowledge Cardiff University for financial support as part of the MAXNET Energy Consortium. C.J.K. acknowledges funding from the NSF Major Research Instrumentation program (grant MRI/DMR-1040229). S.M.A. thanks the Saudi Arabian government for his $\mathrm{Ph} . \mathrm{D}$. scholarship. All results are reported in the main text and supplementary materials.

\section{References}

[1] International Energy Agency, Resources to Reserves 2013 - Oil, Gas and Coal Technologies for the Energy Markets of the Future, 2013. doi:10.1787/9789264090705-en.

[2] R.G. Bergman, Organometallic chemistry: C-H activation, Nature. 446 (2007) 391394. doi:10.1038/446391a.

[3] D.. Wilhelm, D.. Simbeck, A.. Karp, R.. Dickenson, Syngas production for gas-toliquids applications: technologies, issues and outlook, Fuel Process. Technol. 71 (2001) 139-148. doi:10.1016/S0378-3820(01)00140-0.

[4] J.-P. Lange, K.P. de Jong, J. Ansorge, P.J.A. Tijm, Keys to methane conversion technologies, Stud. Surf. Sci. Catal. 107 (1997) 81-86. doi:10.1016/S01672991(97)80320-5.

[5] M. Ravi, M. Ranocchiari, J.A. van Bokhoven, The Direct Catalytic Oxidation of Methane to Methanol-A Critical Assessment, Angew. Chemie Int. Ed. 56 (2017) 16464-16483. doi:10.1002/anie.201702550.

[6] A.R. Kulkarni, Z.-J. Zhao, S. Siahrostami, J.K. Nørskov, F. Studt, Cation-exchanged zeolites for the selective oxidation of methane to methanol, Catal. Sci. Technol. 8 (2018) 114-123. doi:10.1039/C7CY01229B.

[7] C. Hammond, S. Conrad, I. Hermans, Oxidative Methane Upgrading, ChemSusChem. 5 (2012) 1668-1686. doi:10.1002/cssc.201200299.

[8] R.A. Periana, D.J. Taube, S. Gamble, H. Taube, T. Satoh, H. Fujii, Methanol Derivative Platinum Catalysts for the High-Yield Oxidation of Methane to a Methanol Derivative, Science (80-. ). 280 (1998) 560-564. doi:10.1126/science.280.5363.560.

[9] Q. Yuan, W. Deng, Q. Zhang, Y. Wang, Osmium-catalyzed selective oxidations of methane and ethane with hydrogen peroxide in aqueous medium, Adv. Synth. Catal. 349 (2007) 1199-1209. doi:10.1002/adsc.200600438.

[10] L.C. Kao, A.C. Hutson, A. Sen, Low-Temperature, Palladium(II)-Catalyzed, Solution- 
Phase Oxidation of Methane to a Methanol Derivative, J. Am. Chem. Soc. 113 (1991) 700-701. doi:10.1021/ja00002a063.

[11] M. Ahlquist, R.J. Nielsen, R.A. Periana, W.A. Goddard III, Product Protection, the Key to Developing High Performance Methane Selective Oxidation Catalysts, J. Am. Chem. Soc. 131 (2009) 17110-17115. doi:10.1021/ja903930e.

[12] C.J. Jones, D. Taube, V.R. Ziatdinov, R.A. Periana, R.J. Nielsen, J. Oxgaard, W.A. Goddard, Selective oxidation of methane to methanol catalyzed, with $\mathrm{C}-\mathrm{H}$ activation, by homogeneous, cationic gold, Angew. Chemie - Int. Ed. 43 (2004) 4626-4629. doi:10.1002/anie.200461055.

[13] C. Hammond, M.M. Forde, M.H. Ab Rahim, A. Thetford, Q. He, R.L. Jenkins, N. Dimitratos, J.A. Lopez-Sanchez, N.F. Dummer, D.M. Murphy, A.F. Carley, S.H. Taylor, D.J. Willock, E.E. Stangland, J. Kang, H. Hagen, C.J. Kiely, G.J. Hutchings, Direct catalytic conversion of methane to methanol in an aqueous medium by using copper-promoted Fe-ZSM-5, Angew. Chemie - Int. Ed. 51 (2012) 5129-5133. doi:10.1002/anie.201108706.

[14] C. Hammond, R.L. Jenkins, N. Dimitratos, J.A. Lopez-Sanchez, M.H. ab Rahim, M.M. Forde, A. Thetford, D.M. Murphy, H. Hagen, E.E. Stangland, J.M. Moulijn, S.H. Taylor, D.J. Willock, G.J. Hutchings, Catalytic and Mechanistic Insights of the LowTemperature Selective Oxidation of Methane over Cu-Promoted Fe-ZSM-5, Chem. - A Eur. J. 18 (2012) 15735-15745. doi:10.1002/chem.201202802.

[15] L. Kesavan, R. Tiruvalam, M. Hasbi, A. Rahim, M. Izham, D.I. Enache, R.L. Jenkins, N. Dimitratos, J.A. Lopez-sanchez, S.H. Taylor, D.W. Knight, C.J. Kiely, G.J. Hutchings, Solvent-Free Oxidation of Primary Carbon-Hydrogen Bonds in Toluene Using Au-Pd Alloy Nanoparticles, Science (80-. ). 331 (2011) 195-199.

[16] A. Villa, N. Dimitratos, C.E. Chan-Thaw, C. Hammond, L. Prati, G.J. Hutchings, Glycerol oxidation using gold-containing catalysts, Acc. Chem. Res. 48 (2015) 14031412. doi:10.1021/ar500426g.

[17] J. Pritchard, L. Kesavan, M. Piccinini, Q. He, R. Tiruvalam, N. Dimitratos, J.A. Lopez-Sanchez, A.F. Carley, J.K. Edwards, C.J. Kiely, G.J. Hutchings, Direct synthesis of hydrogen peroxide and benzyl alcohol oxidation using Au-Pd catalysts prepared by sol immobilization, Langmuir. 26 (2010) 16568-16577. doi:10.1021/la101597q

[18] M.H. Ab Rahim, M.M. Forde, R.L. Jenkins, C. Hammond, Q. He, N. Dimitratos, J.A. Lopez-Sanchez, A.F. Carley, S.H. Taylor, D.J. Willock, D.M. Murphy, C.J. Kiely, G.J. 
Hutchings, Oxidation of methane to methanol with hydrogen peroxide using supported gold-palladium alloy nanoparticles, Angew. Chemie - Int. Ed. 52 (2013) 1280-1284. doi:10.1002/anie.201207717.

[19] C. Williams, J.H. Carter, N.F. Dummer, Y.K. Chow, D.J. Morgan, S. Yacob, P. Serna, D.J. Willock, R.J. Meyer, S.H. Taylor, G.J. Hutchings, Selective Oxidation of Methane to Methanol Using Supported AuPd Catalysts Prepared by Stabilizer-Free SolImmobilization, ACS Catal. 8 (2018) 2567-2576. doi:10.1021/acscatal.7b04417.

[20] J.K. Edwards, S.J. Freakley, A.F. Carley, C.J. Kiely, G.J. Hutchings, Strategies for Designing Supported Gold-Palladium Bimetallic Catalysts for the Direct Synthesis of Hydrogen Peroxide, Acc. Chem. Res. 47 (2013) 845-854. doi:10.1021/ar400177c.

[21] N. Agarwal, S.J. Freakley, R.U. McVicker, S.M. Althahban, N. Dimitratos, Q. He, D.J. Morgan, R.L. Jenkins, D.J. Willock, S.H. Taylor, C.J. Kiely, G.J. Hutchings, Aqueous Au-Pd colloids catalyze selective $\mathrm{CH}_{4}$ oxidation to $\mathrm{CH}_{3} \mathrm{OH}$ with $\mathrm{O}_{2}$ under mild conditions, Science (80-. ). 358 (2017) 223-227. doi:10.1126/science.aan6515.

[22] J.A. Lopez-Sanchez, N. Dimitratos, P. Miedziak, E. Ntainjua, J.K. Edwards, D. Morgan, A.F. Carley, R. Tiruvalam, C.J. Kiely, G.J. Hutchings, Au-Pd supported nanocrystals prepared by a sol immobilisation technique as catalysts for selective chemical synthesis, Phys. Chem. Chem. Phys. 10 (2008) 1921. doi:10.1039/b719345a.

[23] J. Pritchard, M. Piccinini, R. Tiruvalam, Q. He, N. Dimitratos, J.A. Lopez-Sanchez, D.J. Morgan, A.F. Carley, J.K. Edwards, C.J. Kiely, G.J. Hutchings, Effect of heat treatment on $\mathrm{Au}-\mathrm{Pd}$ catalysts synthesized by sol immobilisation for the direct synthesis of hydrogen peroxide and benzyl alcoholoxidation, Catal. Sci. Technol. 3 (2013) 308-317. doi:10.1039/C2CY20234D.

[24] A.. Venezia, V. La Parola, G. Deganello, B. Pawelec, J.L.. Fierro, Synergetic effect of gold in $\mathrm{Au} / \mathrm{Pd}$ catalysts during hydrodesulfurization reactions of model compounds, J. Catal. 215 (2003) 317-325. doi:10.1016/S0021-9517(03)00005-8.

[25] D. Wang, X. Cui, Q. Xiao, Y. Hu, Z. Wang, Y.M. Yiu, T.K. Sham, Electronic behaviour of Au-Pt alloys and the 4f binding energy shift anomaly in Au bimetallicsX-ray spectroscopy studies, AIP Adv. 8 (2018) 065210. doi:10.1063/1.5027251.

[26] M.H. Ab Rahim, M.M. Forde, R.L. Jenkins, C. Hammond, Q. He, N. Dimitratos, J.A. Lopez-Sanchez, A.F. Carley, S.H. Taylor, D.J. Willock, D.M. Murphy, C.J. Kiely, G.J. Hutchings, Oxidation of Methane to Methanol with Hydrogen Peroxide Using Supported Gold-Palladium Alloy Nanoparticles, Angew. Chemie. 125 (2013) 13181322. doi:10.1002/ange.201207717. 
[27] M.H. Ab Rahim, M.M. Forde, C. Hammond, R.L. Jenkins, N. Dimitratos, J.A. LopezSanchez, A.F. Carley, S.H. Taylor, D.J. Willock, G.J. Hutchings, Systematic study of the oxidation of methane using supported gold palladium nanoparticles under mild aqueous conditions, Top. Catal. 56 (2013) 1843-1857. doi:10.1007/s11244-013-01213.

[28] M.H. Ab Rahim, R.D. Armstrong, C. Hammond, N. Dimitratos, S.J. Freakley, M.M. Forde, D.J. Morgan, G. Lalev, R.L. Jenkins, J.A. Lopez-Sanchez, S.H. Taylor, G.J. Hutchings, Low temperature selective oxidation of methane to methanol using titania supported gold palladium copper catalysts, Catal. Sci. Technol. 6 (2016) 3410-3418. doi:10.1039/C5CY01586C.

[29] S. Al-Shihri, C.J. Richard, D. Chadwick, Selective Oxidation of Methane to Methanol over ZSM-5 Catalysts in Aqueous Hydrogen Peroxide: Role of Formaldehyde, ChemCatChem. 9 (2017) 1276-1283. doi:10.1002/cctc.201601563.

[30] G.B. Shul'pin, G.V. Nizova, Y.N. Kozlov, L. Gonzalez Cuervo, G. Süss-Fink, Hydrogen Peroxide Oxygenation of Alkanes Including Methane and Ethane Catalyzed by Iron Complexes in Acetonitrile, Adv. Synth. Catal. 346 (2004) 317-332. doi:10.1002/adsc.200303147.

[31] Z. Duan, N. Møller, J. Greenberg, J.H. Weare, The prediction of methane solubility in natural waters to high ionic strength from 0 to $250^{\circ} \mathrm{C}$ and from 0 to $1600 \mathrm{bar}$, Geochim. Cosmochim. Acta. 56 (1992) 1451-1460. doi:10.1016/00167037(92)90215-5.

[32] J. Kiepe, S. Horstmann, A. Kai Fischer, J. Gmehling, Experimental Determination and Prediction of Gas Solubility Data for Methane + Water Solutions Containing Different Monovalent Electrolytes, Ind. Eng. Chem. Res. 42 (2003) 5392-5398. doi:10.1021/IE030386X.

[33] J. Colby, D.I. Stirling, H. Dalton, The Soluble Methane Mono-oxygenase of Methylococcus capsulatus (Bath), Biochem. J. 165 (1977) 395-402.

[34] J. Shan, M. Li, L.F. Allard, S. Lee, M. Flytzani-Stephanopoulos, Mild oxidation of methane to methanol or acetic acid on supported isolated rhodium catalysts, Nature. 551 (2017) 605-608. doi:10.1038/nature24640.

[35] V.L. Sushkevich, D. Palagin, M. Ranocchiari, J.A. van Bokhoven, Selective anaerobic oxidation of methane enables direct synthesis of methanol, Science (80-. ). 356 (2017) 523-527. doi:10.1016/S0166-9834(00)80103-7. 

Figure 1 a) Representative BF-TEM image and particle size distribution and b) XPS analysis of the Au-Pd-PVP colloid. Plot (a) corresponds to $\mathrm{Au}(4 \mathrm{f})$ and (b) corresponds to Pd(3d). Plot (b) also shows presence of $\mathrm{Au}(4 \mathrm{~d})$ signals.

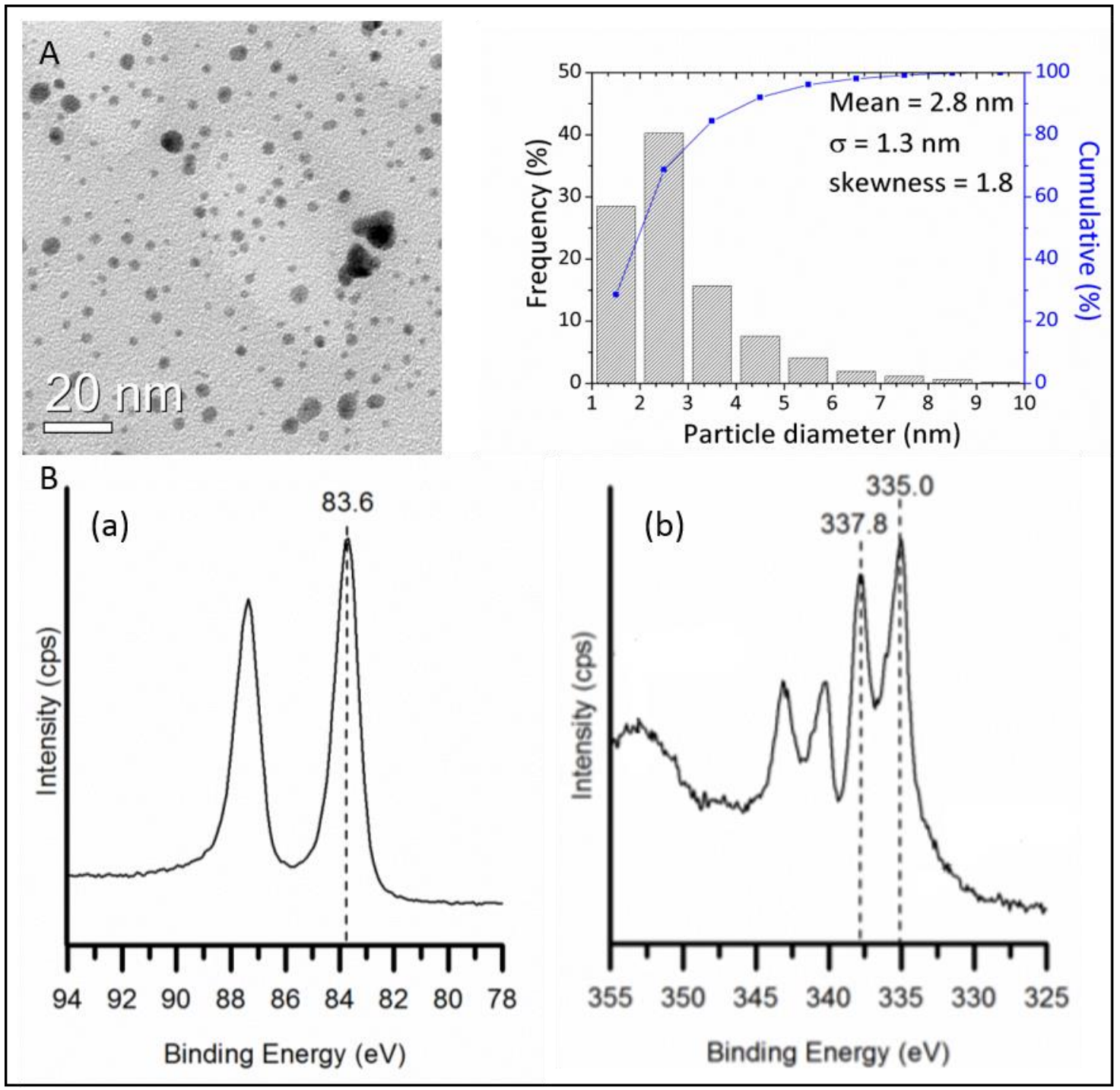


Figure 2. Time-on-line analysis of product distribution for methane oxidation using $\mathrm{Au}-\mathrm{Pd}$ PVP colloids with $\mathrm{H}_{2} \mathrm{O}_{2}$. Test Conditions - $5000 \mu \mathrm{mol} \mathrm{H}_{2} \mathrm{O}_{2}, 50{ }^{\circ} \mathrm{C}$, total volume $10 \mathrm{ml}, p \mathrm{CH}_{4}$ 30 bar, $1500 \mathrm{rpm}, 7.57 \mu \mathrm{mol}$ metal per reaction. Colloid; PVP : metal =1.2:1, $\mathrm{Au}: \mathrm{Pd}=1: 1$ molar, $[$ metal $]=7.57 \times 10^{-4} \mathrm{M}$.

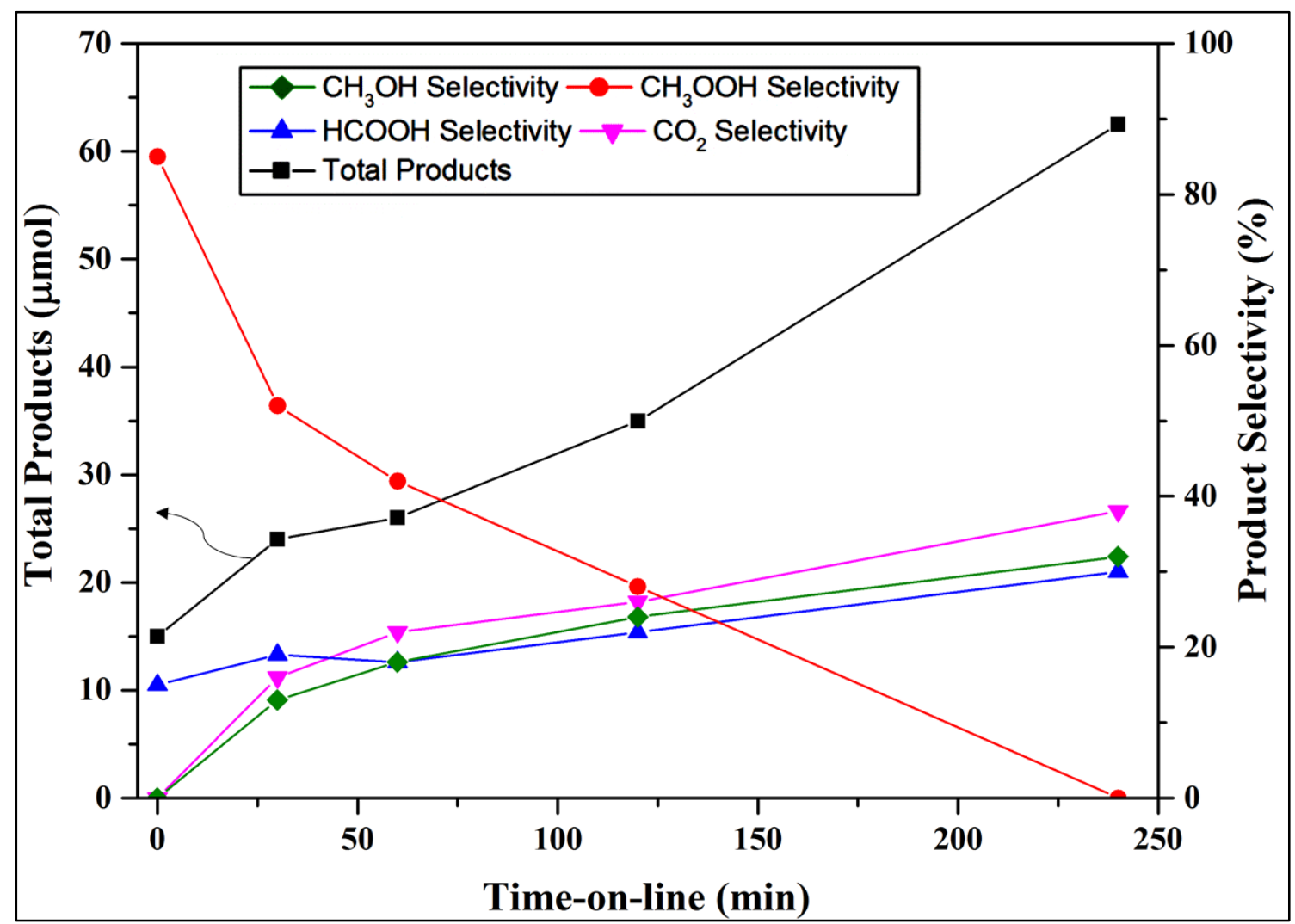


Scheme 1. Proposed reaction scheme based on temporal selectivity.

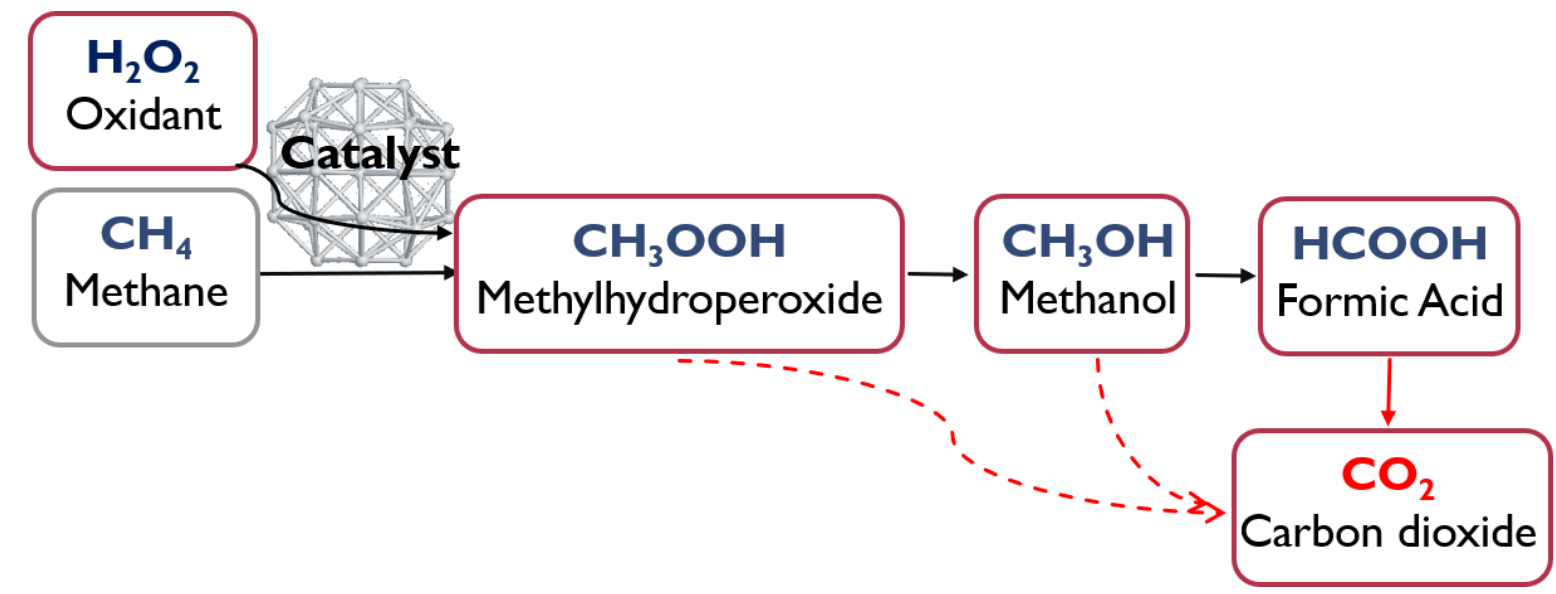

Figure 3. Methane oxidation reactions carried out at various temperatures using Au-Pd-PVP colloids and $\mathrm{H}_{2} \mathrm{O}_{2}$. Test Conditions $-1000 \mu \mathrm{mol} \mathrm{H} \mathrm{H}_{2}$, total volume $10 \mathrm{ml}, p \mathrm{CH}_{4} 30$ bar, $0.5 \mathrm{~h}$, $1500 \mathrm{rpm}, 7.57 \mu \mathrm{mol}$ metal per reaction. Colloid; PVP : metal = 1.2:1, $\mathrm{Au}: \mathrm{Pd}=1: 1$ molar, $[$ metal $]=7.57 \times 10^{-4} \mathrm{M}$.

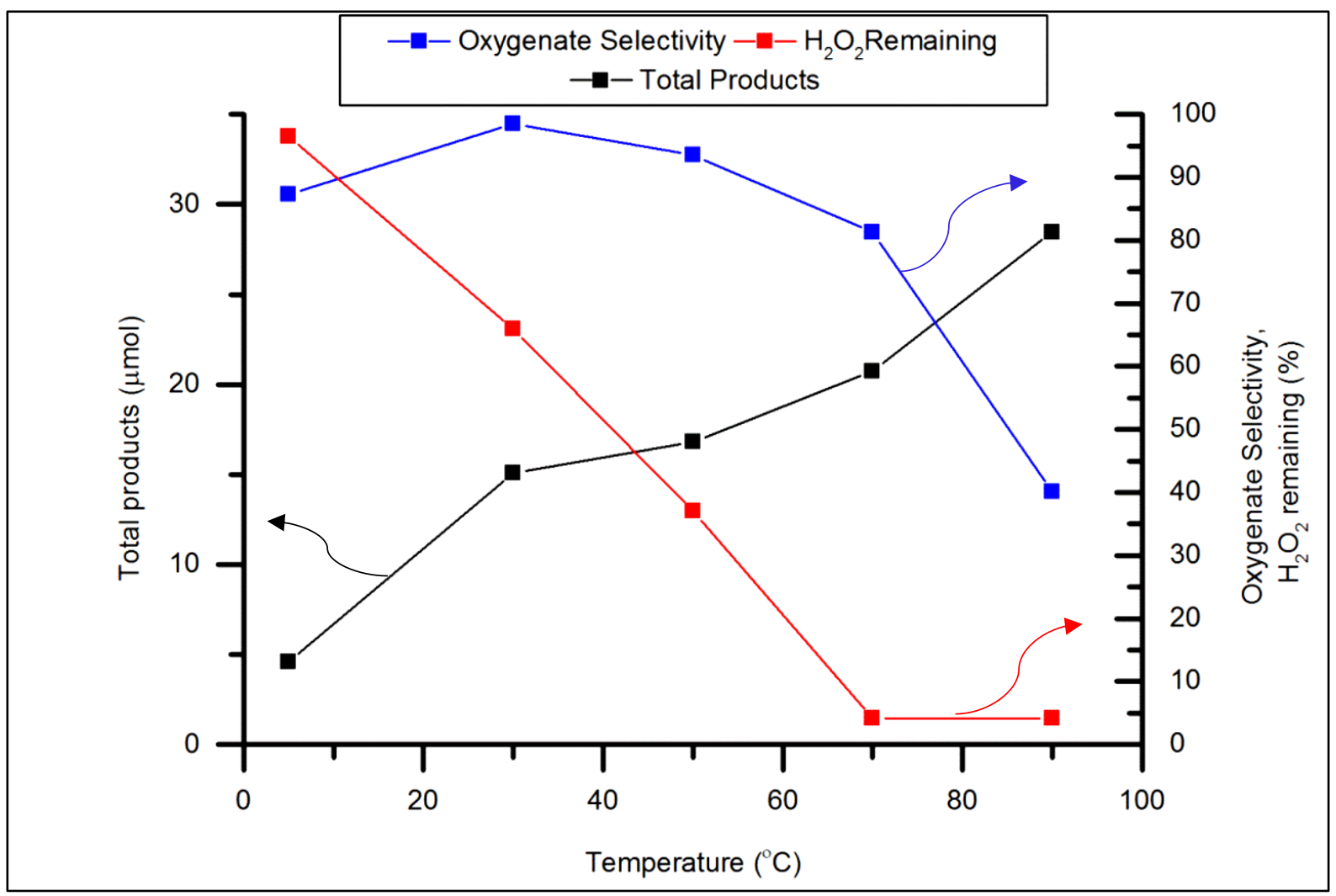


Figure 4. Methane oxidation reactions carried out using colloidal Au-Pd nanoparticles and $\mathrm{H}_{2} \mathrm{O}_{2}$ under various pressures of $\mathrm{CH}_{4}$. Test Conditions - $1000 \mu \mathrm{mol}_{2} \mathrm{O}_{2}, 50{ }^{\circ} \mathrm{C}$, total volume $10 \mathrm{ml}, 0.5 \mathrm{~h}, 1500 \mathrm{rpm}, 7.57 \mu \mathrm{mol}$ metal per reaction. Colloid; $\mathrm{PVP}:$ metal =1.2:1, $\mathrm{Au}: \mathrm{Pd}=$ $1: 1$ molar, $[$ metal $]=7.57 \times 10^{-4} \mathrm{M}$.

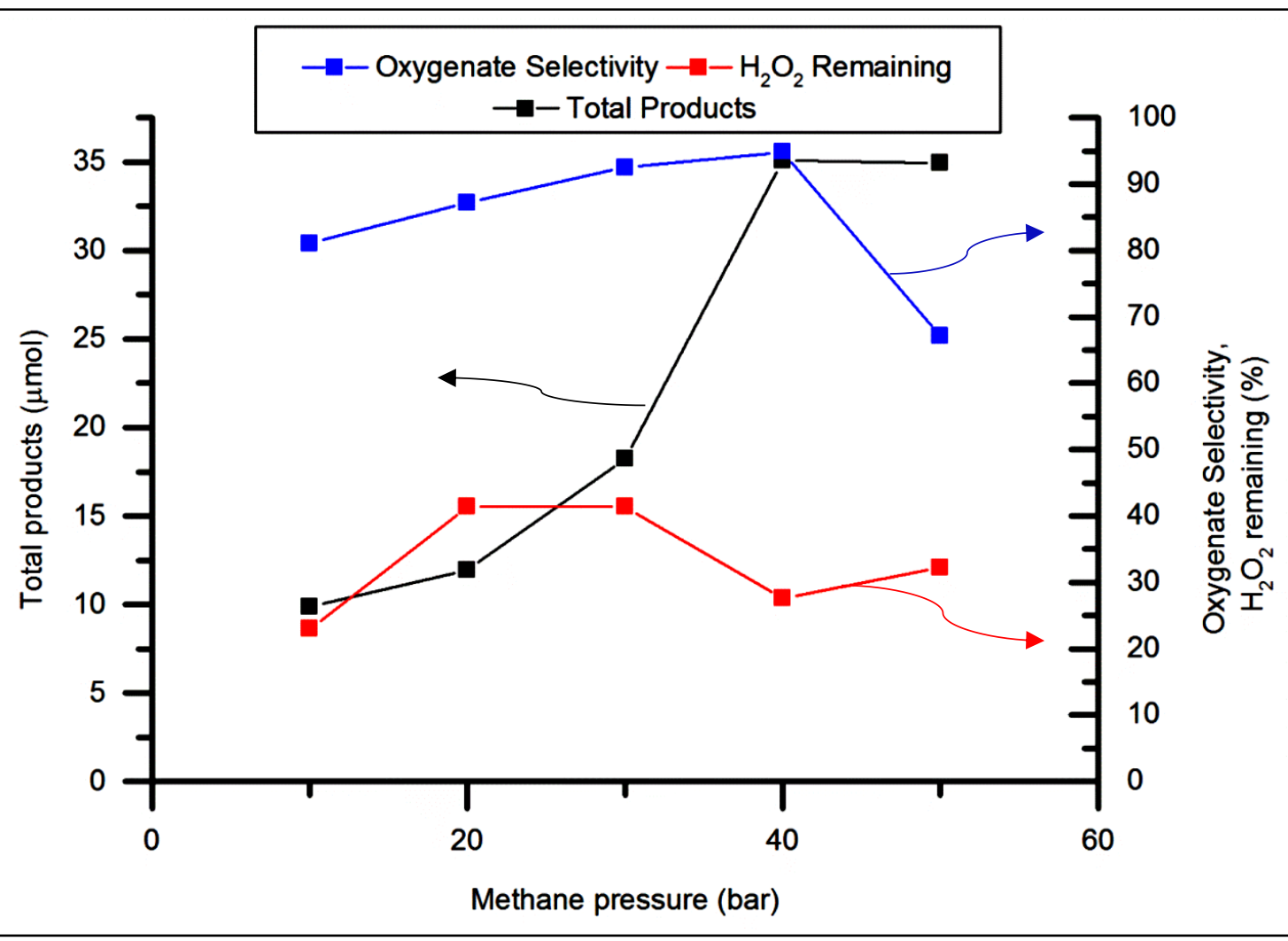


Figure 5. Methane oxidation reactions carried out using colloidal Au-Pd nanoparticles and various initial concentrations of $\mathrm{H}_{2} \mathrm{O}_{2}$. Test Conditions $-50{ }^{\circ} \mathrm{C}$, total volume $10 \mathrm{ml}, 30 \mathrm{bar}, 0.5$ h, $1500 \mathrm{rpm}, 7.57 \mu \mathrm{mol}$ metal per reaction. Colloid; $\mathrm{PVP}:$ metal = 1.2:1, $\mathrm{Au}: \mathrm{Pd}=1: 1 \mathrm{molar}$, $[$ metal $]=7.57 \times 10^{-4} \mathrm{M}$.

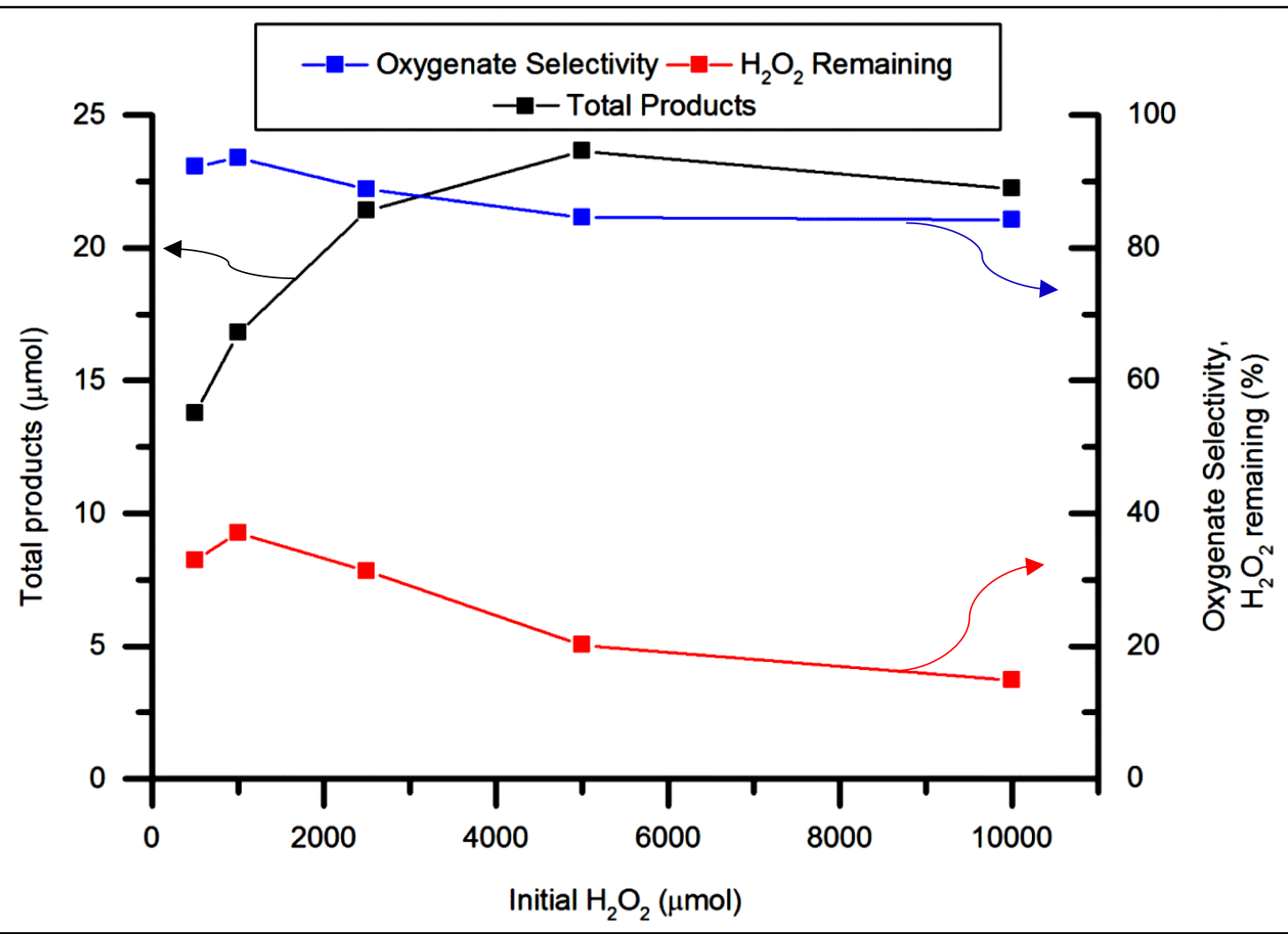


Figure 6. Methane oxidation reactions carried out using colloidal Au-Pd nanoparticles and $\mathrm{H}_{2} \mathrm{O}_{2}$ where the system was subjected to various stirring speeds. Test Conditions - $1000 \mu \mathrm{mol}$ $\mathrm{H}_{2} \mathrm{O}_{2}, 50{ }^{\circ} \mathrm{C}$, total volume $10 \mathrm{ml}, 30$ bar, $0.5 \mathrm{~h}, 7.57 \mu$ mol metal per reaction. Colloid; PVP : metal $=1.2: 1, \mathrm{Au}: \mathrm{Pd}=1: 1$ molar, $[$ metal $]=7.57 \times 10^{-4} \mathrm{M}$.

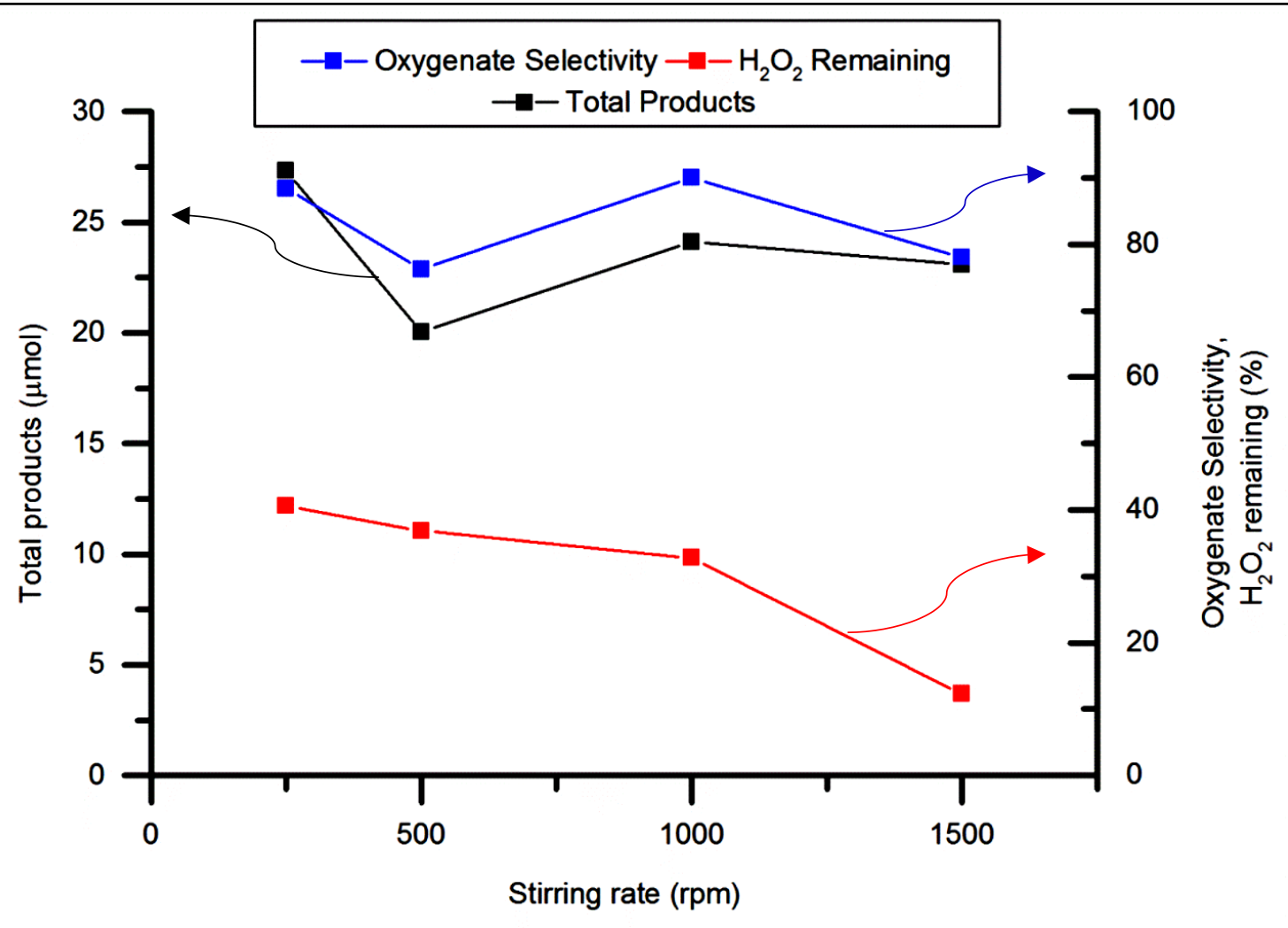


Figure 7. Methane oxidation reactions carried out with $\mathrm{H}_{2} \mathrm{O}_{2}$ and colloidal $\mathrm{Au}-\mathrm{Pd}$ nanoparticles with various metal concentrations. Test Conditions - $1000 \mu \mathrm{mol} \mathrm{H}_{2} \mathrm{O}_{2}, 50{ }^{\circ} \mathrm{C}$, total volume 10 $\mathrm{ml}, p \mathrm{CH}_{4} 30$ bar, $0.5 \mathrm{~h}, 7.57 \mu \mathrm{mol}$ metal per reaction. Colloid; $\mathrm{PVP}:$ metal $=1.2: 1, \mathrm{Au}: \mathrm{Pd}=$ $1: 1$ molar.

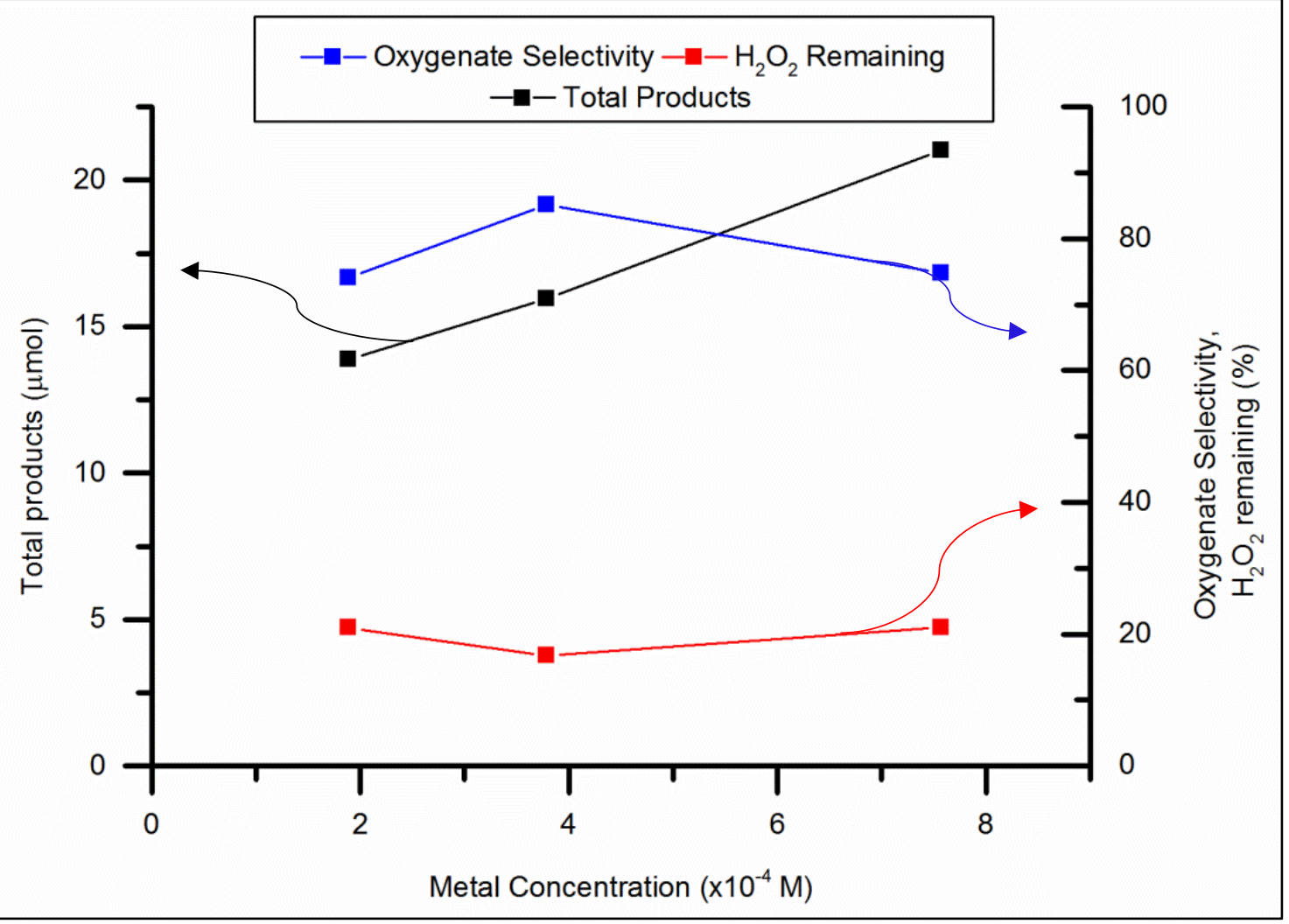


Figure 8. $\mathrm{CH}_{4}$ oxidation reactions carried out with $\mathrm{H}_{2} \mathrm{O}_{2}$ and colloidal $\mathrm{Au}-\mathrm{Pd}$ nanoparticles with various amounts of $\mathrm{NaCl}$ added to the reactor. Test Conditions $-1000 \mu \mathrm{mol} \mathrm{H}_{2} \mathrm{O}_{2}, 50{ }^{\circ} \mathrm{C}$, total volume $10 \mathrm{ml}, \mathrm{pCH}_{4} 30$ bar, $0.5 \mathrm{~h}, 7.57 \mu \mathrm{mol}$ metal per reaction. Colloid; $\mathrm{PVP}:$ metal = 1.2:1, $\mathrm{Au}: \mathrm{Pd}=1: 1$ molar, $[$ metal $]=7.57 \times 10^{-4} \mathrm{M}$.

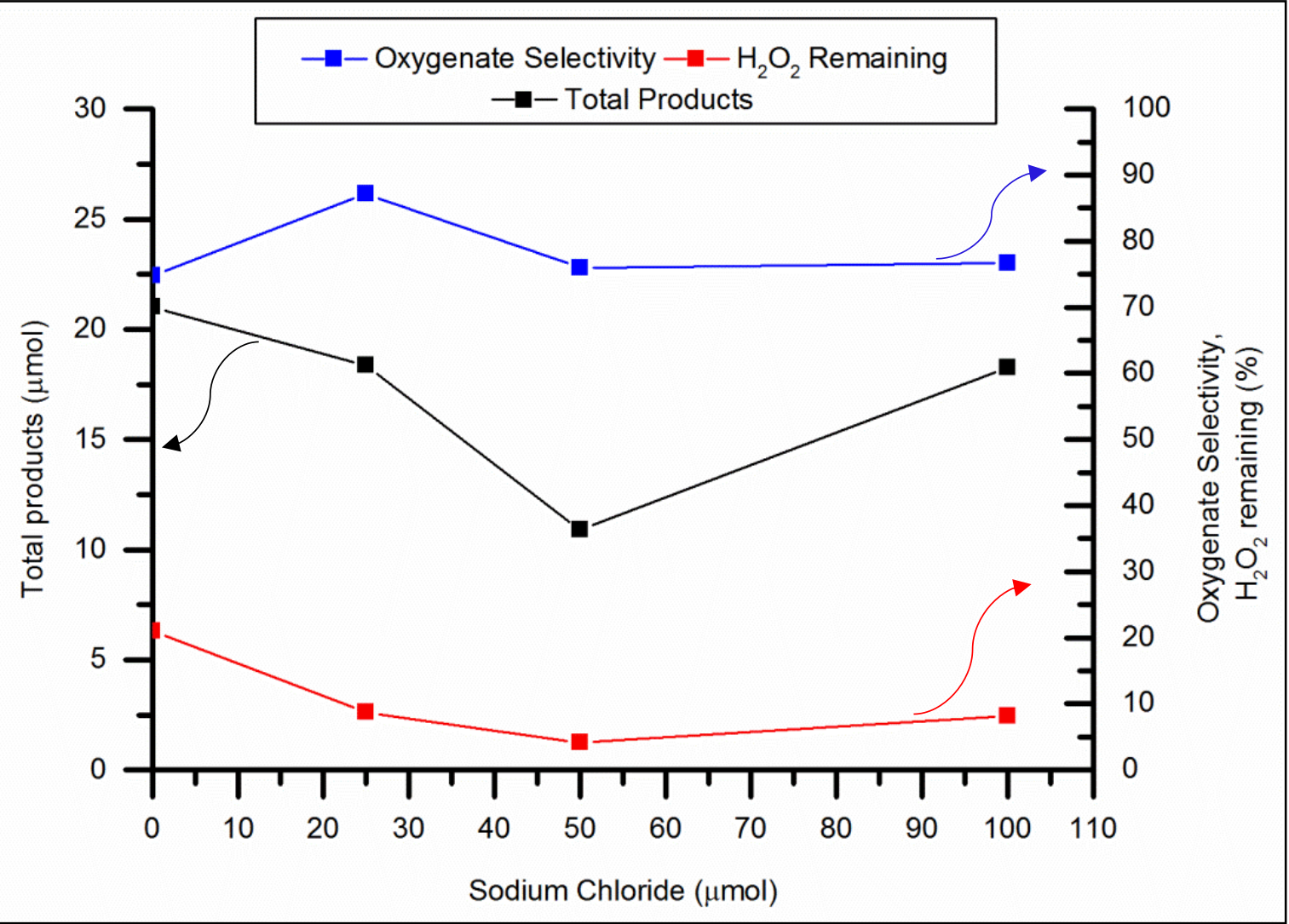


Figure 9. Effect of PVP molecular weight on catalytic activity of colloidal Au-Pd nanoparticles for $\mathrm{CH}_{4}$ oxidation with $\mathrm{H}_{2} \mathrm{O}_{2}$. Test Conditions - $1000 \mu \mathrm{mol}_{2} \mathrm{O}_{2}, 50{ }^{\circ} \mathrm{C}$, total volume $10 \mathrm{ml}$, $p \mathrm{CH}_{4} 30$ bar, 0.5 h, $7.57 \mu$ mol metal per reaction. Colloid; PVP : metal = 1.2:1, $\mathrm{Au}: \mathrm{Pd}=1: 1$ molar, $[$ metal $]=7.57 \times 10^{-4} \mathrm{M}$.

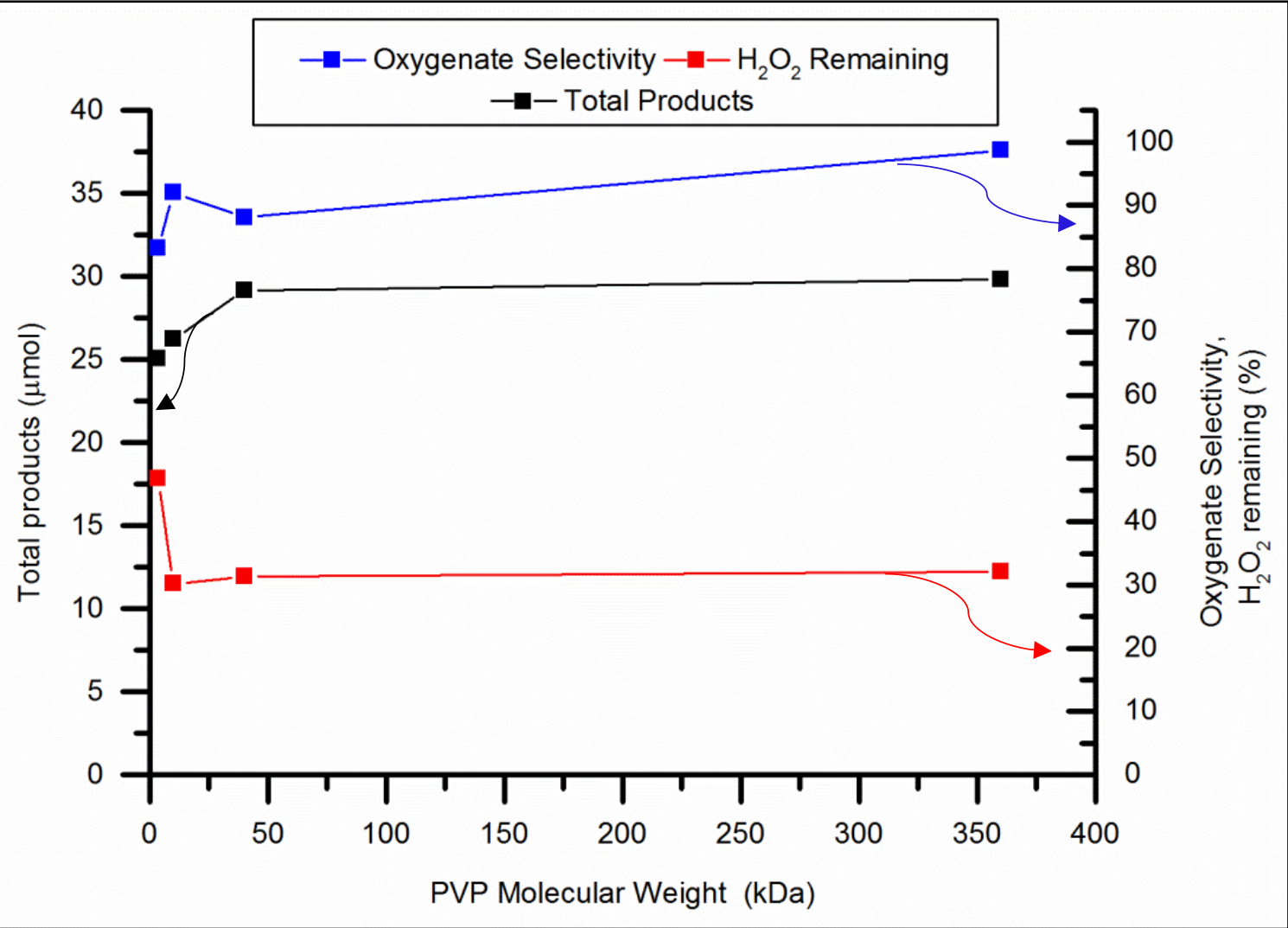

